
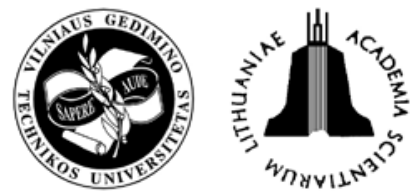

TRANSPORT

2009

24(1): 37-41

\title{
ALLOTMENT BOOKING IN INTERMODAL TRANSPORT
}

\author{
Ilona Jaržemskiené ${ }^{1}$, Vytautas Jaržemskis ${ }^{2}$ \\ Vilnius Gediminas Technical University, Plytinès g. 27, 10105 Vilnius, Lithuania \\ ${ }^{1}$ Transport Research Institute, e-mail: ilona@ti.vgtu.lt \\ ${ }^{2}$ Dept of Transport Management, e-mail: vytautas.jarzemskis@ti.vgtu.lt
}

Received 21 April 2008; accepted 12 January 2009

\begin{abstract}
The article presents a valuable concept seeking to solve the problem of demand uncertainty in intermodal transport. Regular traffic is quite important for moving containers, trailers and swap bodies. To keep regularity with uncertain demand means to have backlogs or empty space. Both of them are inefficient from an economical point of view. In practice, a day-by-day demand forecast is meaningful only for the next two or three days. This poses serious allotment management problems to freight forwarders and shippers since long-term contract allotments need to be planned many months ahead. The article presents a stochastic dynamic programming model for a short-term allotment planning a model that would be very valuable for implementing intermodal solutions. The presented model evaluates optimal cost policy based on the economic trade-off between the cost of backlogged shipment and the cost of acquiring additional allotment.
\end{abstract}

Keywords: allotment, stochastic model, intermodal transport.

\section{Introduction}

The relevance of this article is based on the allotment of railcars forecasting in the transportation of intermodal transport units. Containerisation is booming all over the world creating new challenges for the whole transport system. The growing market for freight transportation is dramatically provoking an increase in road transportation. Wihtin the period from 1970 to 2000, the share of road transport in Europe increased by 22 percent. A differen situation can be observed in the railway sector as during the same period, railway freight traffic decreased by 18 percent.

The picture is different in the U.S. where rail transport plays a crucial role, whereas in the EU, it comes only in the third position. The history of railway construction in America and Europe is different. Bookbinder and Fox (1998) clearly presented intermodal routing in North America. Railways in the U.S. were built on the basis of private investments. Entrepreneurship is highly developed in this sector comparing to that in Europe where the main railway lines in different countries were built by the Government, i.e. tax payers. Railway operators also own the infrastructure in the U.S. Freight transportation using railways is the core business of railway companies. Due to an economy of scale, railways successfully compete with road transportation. For a number of years, railway passenger transport, rather than freight, has been given priority in Europe. Thus, it is really difficult to compete with a truck when the level of priority comes only second. This is one of the reasons why the U.S. takes a dominant position in the field of rail-based intermodal decisions in comparison to the E.U. Containers on flat cars (COFC) are the main and growing market segment for intermodal train operators in the U.S. Intermodal trains in the U.S. successfully compete with trucks on the main routes with an average speed of $26.6 \mathrm{~km}$ per hour (640 km per day) for the containers on flat car (COFC) concept and $46.6 \mathrm{~km}$ per hour (1120 km per day) for the trailers on flat car concept In both cases, they mostly provide daily and regular service.

The economy of scale is the main driving force for intermodality clearly presented by Evers (1994) and Trip and Bontekoning (2002) who primarily concentrate on small scale intermodality.

Jaržemskis (2008) presented the assumptions of small-scale intermodal transport. Vasilis Vasiliauskas and Barysienè (2008a) analyzed the possibilities of Lithuanian transport sector in the context of European-Asian trade relations. Vasilis Vasiliauskas and Barysienè (2008b) analyzed an economic evaluation model of the logistic system based on container transportation. Miao and Xi (2008) studied the quantitative forecasting method for the agile forecasting logistics demand for a dynamic supply chain environment. Lingaitienè (2008) investigated a mathematical model of selecting transport facilities for multimodal freight transportation. Jaržemskienè (2007) researched the problems of the evolution and development of intermodal transport. Vasilis Vasiliauskas (2006) is modelling the performance of railway nodes as intermodal terminals. The development of inter- 
modal transport in the new member states of the European Union states is investigated by Šakalys and Palšaitis (2006).

The main accent on promoting intermodal transport in the EU is included in the environmental area, as declared in 'White Paper - European transport policy for 2010: Time to decide' (2001). Pollution, congestion and accidents are important issues for revising the situation and supporting intermodal decisions. Certainly, the environmental aspects are a strong tool for politicians and public opinion, however, business uses the language of money. At the moment, the need for stronger economical promotion has arisen in the E.U. The promoters of intermodality should carefully evaluate the current situation and implement the required measures. Business sectors are not satisfied when the decisions on the issues of intermodality are debated and clarified by politicians (GETC/G4384/ SPR 2003). First, education, training and promotion in intermodal transport should be economically targeted. Certainly, environmental issues may be crucial, however, it can play a secondary role in business.

Nowadays, road carriers, forwarding agents and logistics suppliers ('freight integrators' - jargon coined by Brussels) are the main players in shaping combined transport. They have equipment and maintain relations with shippers. Railway, inland waterway and short sea shipping companies are subcontractors in the intermodal chain.

In GETC/G4384/SPR (2003), a variety of European intermodal transport markets having individual peculiarities is usefully summarized. The ideas of intermodal transport sometimes presented by politicians are not competitive with road transport. Finding and fixing a niche in the market is an important question adressed to intermodal transport. One of the market niches is a shipment of maritime containers arriving in European ports like Hamburg, Bremerhafen, Rotterdam, Antwerp, Le Havre, Marseille, Genua, Gióia Tauro etc. Freight is transferred to the destinations in Europe using either short sea shipping or railway transport. The distribution of maritime containers by road only takes place over distances shorter than $500 \mathrm{~km}$ or in cases when containers are finally brought to or from the port. The other market niche is the transportation of tank containers. Wherever possible, these are conveyed in combined transport. All tank containers moving combined make the use of rail/road possibilities and no political initiatives are needed to persuade road transport operators to use the railway infrastructure. The newest private railway operators come from this sector. The unaccompanied transport of swap bodies and semi-trailers is the third niche of the intermodal market. The distance of transportation, frequency, delivery time and prices are the main competitive factors in this niche. It is exactly the market, shared by European truck services because railways did not understand how they should go about playing their role in the international chain. As long as the railways, as monopolies with a dominant position, do not look after their rail haulage services but devote more time and resources towards consolidating their general market position, the level of intermodality in the semi-trailers and swap bodies market will be low.
The next reason for lack of intermodality could be blamed on lack of the punctuality of freight trains. The delays of up to 24 hours became the norm and this is supposed to be only a tip of the iceberg. The core is lack of understanding about the volume of a negative effect inspired by delays. According to CIM provisions, under which trains, in principle, can be delayed for up to 7 days before, compensation has to be paid. The railways suggest compensations but not changes. Various kinds of subsidies are given to intermodal transport. Compensation and subsidies are focused on decreasing consequences rather than reasons. The punctuality problems of freight railways arise because of the priority of passenger trains over freight in Europe. In the cases of accidents and failures of timetables, passenger trains are rescheduled first. Freight trains are moved to a position where a free time window is obtained.

Lack of railcars is also a crucial problem, especially in Eastern Europe where freight carriage is under SMGS rules and the standard of the railway system is a $1520 \mathrm{~mm}$ width gauge ('Russian' Standard). Railway companies do not react to the market demand in railcars because of an uncertain demand. Most containers are shipped by truck operators instead of railways.

Lack of the flexibility of railway timetables, capacities and prices is another matter of intermodality. Market prices fluctuate during the various seasons of the year but the railway companies do nothing to meet the market conditions. The next problem arises due to lack of equipment suitable for combined freight transport. Investment in intermodal equipment is not a major priority for the national railways of the EU Member States.

The next problem that meets intermodal transport is regional differences in Europe. The economical gap between regions cause the different prices of workforce. This means that trucking prices per kilometre are different in various regions, e.g. Scandinavia and Baltic Sates or Baltic States and the UK. This is because trailers carried by railway and/or a ferry are accompanied by both trucks and drivers. At the moment, to send a truck and a driver from a new Member State is cheaper than in comparison to buy trucking service, e.g. in Scandinavia and/or the UK. However, the additional eight tons of track weight do not match an ecological and economical background of intermodality as a whole system. The additional eight tons is more than 60 percent of the average weight of freight in trailers that was 13 tons per trailer in Klaipeda port in 2006. The analysed possibility was to locate one's own trucks in Scandinavia and/or the UK. Nevertheless, certain cabotage restrictions exist. According to the EU law, this restriction should be cancelled in 2012. Turkey-Italy intermodal connection by ferry was found as an unaccepted practice of intermodality. Trailers carried by a ferry were accompanied by a truck. The drivers of these trucks were sent by bus via the Balkans to meet their trucks.

A negative effect of road transport is calculated as external transport costs. In many countries, external costs are not correctly evaluated nowadays. Road fees as well as fuel and environmental taxes are a costly toll to cover, but it has various measures in the EU. A common policy of calculation should be used across Europe. A comparison of operational cost discloses that railway 
rather than road transport is economically more effective due to the economy of scope. The whole amount of the infrastructure cost of railways is covered by railway operators today. The infrastructure costs of road transport are covered by commercial operators as well as by private users and tax payers.

However, a conclusion that railway companies in Europe should change their thinking of business in order to be more market focused could be made. The article is based on the evaluation of the theoretical assumption to support the intermodal solution due to a stochastic dynamic programming model which may be used for solving problems with an uncertain demand of railcars for TOFC and COFC transportation.

The current forwarding process in the Shuttle train concept makes capacity planning difficult for forwarders and railway companies. Due to high capital investment, regular train schedules and rolling stock capacity are planned and fixed by a railway company for several months. The allotment model shows that freight forwarders could acquire free allotment in ST on a long-term contract basis. In such a contract, capacity is planned to the exact amount of each specific dated departure. Therefore, a long-term booking process requires freight forwarders to commit to allotment ahead of time, which implies that shippers must give freight forwarders their forecasted order fulfillment plans.

There has been very limited work done in capacity planning models for train's shipment. In general, our work to some extent is similar to the model of cargo space booking presented by Chew et al. (2006). Instead of making a decision on the required free space for cargo in an airplane, a decision on the required allotment in the rolling stock of shuttle train for trucks and containers is made. Similar modeling principles can be found in $\mathrm{Ra}-$ man (1999) work where the problem is characterized by a finite selling season and uncertain demand and where several periods of producing or purchasing items to be sold during the selling season may exist.

Another way to solve our scientific problem is routing, scheduling and fleet sizing. Effective local search algorithms for routing and scheduling problems with general time-window constraints are presented in Ibaraki et al. (2005) work. These algorithms and Wu et al. (2005) model of fleet sizing could be successfully adapted along with the above introduced model.

A wide analysis of intermodal transport in a general field is made by Lowe (2005) where the juridical, organisational and technical aspects of intermodal transport in Europe are presented. Forwarders' input in the logistical process is highlighted in works by Burkovskis (2008) and Vasilis Vasiliauskas and Jakubauskas (2007). Forwarding free space is compatible with the Lowe as well as with Ballis and Golias (2004) concepts in which intermodality is assumed as a combined transport chain performance. A similar theory was developed by Joborn et al. (2004).

\section{The Model of Allotment Booking and Formulation of Dynamic Programming}

The current forwarding process in Shuttle train concept makes capacity planning difficult for forwarders and rail- way companies. Due to high capital investment, regular train schedules and rolling stock capacity are planned and fixed by a railway company to last for several months. The allotment model indicates that freight forwarders could acquire free allotment in a shuttle train on a long-term contract basis. Such contract points out that capacity is planned to the exact amount on each specific dated departure. Therefore, a long-term booking process requires freight forwarders to commit to allotment ahead of time which implies that shippers must give freight forwarders their forecasted order fulfilment plans.

Since the amount of TEU to be shipped depends on actual rather than planned orders, this process can create high fluctuation in the allotment requirement.

The situation becomes critical when there is an unexpected amount of orders creating a shortage of the capacity of railcars. Monthly and annually not daily demands can be meaningfully forecasted. In case of an allotment booking model, freight forwarders must pay for any unused allotment in a shuttle train. Furthermore, to anticipate any unexpected growth in demand, freight forwarders may also need to acquire additional allotment at a higher cost to maintain the service level promised to freight owners. The economic analysis trades off between the cost of backlogged containers and the cost of booking additional allotment.

The decision planning model is formulated as a stochastic dynamic programming model where state variables are backlogged orders and decision variables are additional allotment to be booked. At every stage, a decision maker may increase the number of railcars for the next departures at extra cost seeking to avoid a penalty in the future for having backlogged containers.

A reasonable assumption is to model the cost of booking additional allotment by a convex increasing function with respect to additional allotment booked. Any allotment allocated in the period that is not used cannot be returned.

Purchasing allotment in a shuttle train for a specified dated departure takes place in two time periods. The first period is when railway companies sell allotment to freight forwarders on a long-term contract basis. The second one occurs when the departure of the draws approaches. The demand forecast becomes more accurate and freight forwarders may decide on buying additional allotment for containers. This additional allotment frequently could be booked indicating a higher price than the normal long-term based charge. The forecasted daily demands will be meaningful only for the next week. Given these forecasted demands and a long-term allotment allocation, a short-term capacity planning model determines additional allotment required over the next week so that the overall cost is minimized.

Within the process of planning horizon period, there are points defining the cut-off time of a particular train departure. This time, all containers to be sent out on the next departing shuttle train must be delivered to the terminal, i.e. received. Any allotment remaining that is not used cannot be returned. Immediately after the cut-off time, a decision maker has to decide on acquiring additional allotment for the next train departure. This depends on the amount of backlogged cargo 


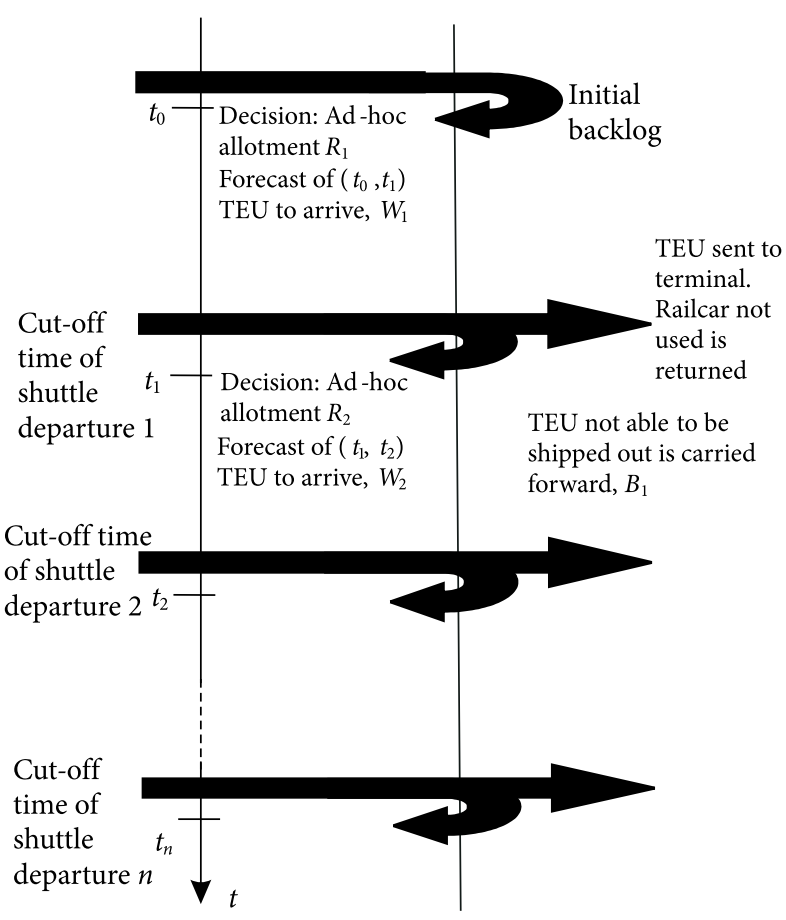

Fig. 1. Short term capacity planning problem of intermodal shuttle operator

remaining as well as on the containers forecasted to be received between this time and the next immediate cutoff time. We restrict our problem to a six-stage problem representing a period of six days. We consider that there is one departure per day. Also we restrict that day-byday demand forecasts are meaningful only for the next six days. The problem can be formulated as a stochastic program which is stated as follows: consider the $i$-th stage. The amount of a backlogged container right after the cut-off time is given. The long-term allotment allocation and forecasted demand are characterized by a probability distribution function. The decision is to acquire allotment $R_{i}$ for the next departure, so that the expected cost to the end of the planning horizon is minimized.

To illustrate the above discussed situation, Jaržemskis (2005) proposed a short-term shuttle train allotment planning model. We ran a dynamic program based on the combinations of parameters given in Table to determine optimal additional allotment to acquire at stage 1 . We considered three discrete and symmetric demand distribution functions including uniform, triangular and truncated normal. All functions have the same mean and similar standard deviations to gauge the robustness of the solution. The obtained results are very similar to those presented by Chew et al. (2006).

Figure 2 shows optimal cost for different combinations of long-term space, additional allotment booking cost functions and initial backlogged containers given that demand distribution is a discrete uniform and the backlogged cost function at the last stage is $3 B^{2}$. The trend confirms the results that the optimal return function at stage 1 is a convex increasing function with respect to the backlogged container.

Optimal additional allotment is given in Figure 3. Figure 4 shows that an optimal quantity of additional al-
Parameters used in the examples

\begin{tabular}{|c|c|}
\hline $\begin{array}{l}\text { Long-term allotment, } \\
\text { A at all stages }\end{array}$ & $\begin{array}{l}\text { 1) } \mu-\delta \\
\text { 2) } \mu \\
\text { 3) } \mu+\delta\end{array}$ \\
\hline \multirow{3}{*}{$\begin{array}{l}\text { Demand distribution } \\
\text { at all stages }\end{array}$} & $\begin{array}{l}\text { 1) Discrete Uniform } \\
\text { Range }=35-105 \\
\mu=70, \delta=20,49\end{array}$ \\
\hline & $\begin{array}{l}\text { 2) Discrete Triangular } \\
\text { Range }=20-120 \\
\mu=70, \delta=20,40\end{array}$ \\
\hline & $\begin{array}{l}\text { 3) Discrete Truncated } \\
\text { Normal Range }=6-134 \\
\mu=70, \delta=20,41\end{array}$ \\
\hline $\begin{array}{l}\text { Ad hoc cost function } \\
\alpha R^{2}+\beta R \text { at all stages }\end{array}$ & $\begin{array}{l}\text { 1) } \alpha=0 ; \beta=1 \\
\text { 2) } \alpha=1 ; \beta=1\end{array}$ \\
\hline $\begin{array}{l}\text { Backlogged cost, } \\
\mathrm{C} \times \mathrm{B} \text { at stages } 1, \ldots, 6\end{array}$ & $C=3$ \\
\hline $\begin{array}{l}\text { Backlogged cost } \gamma B^{\varepsilon} \text {, } \\
\text { at the end of the horizon }\end{array}$ & $\begin{array}{l}\text { 1) } \gamma=3, \varepsilon=2 \\
\text { 2) } \gamma=3, \varepsilon=4\end{array}$ \\
\hline
\end{tabular}

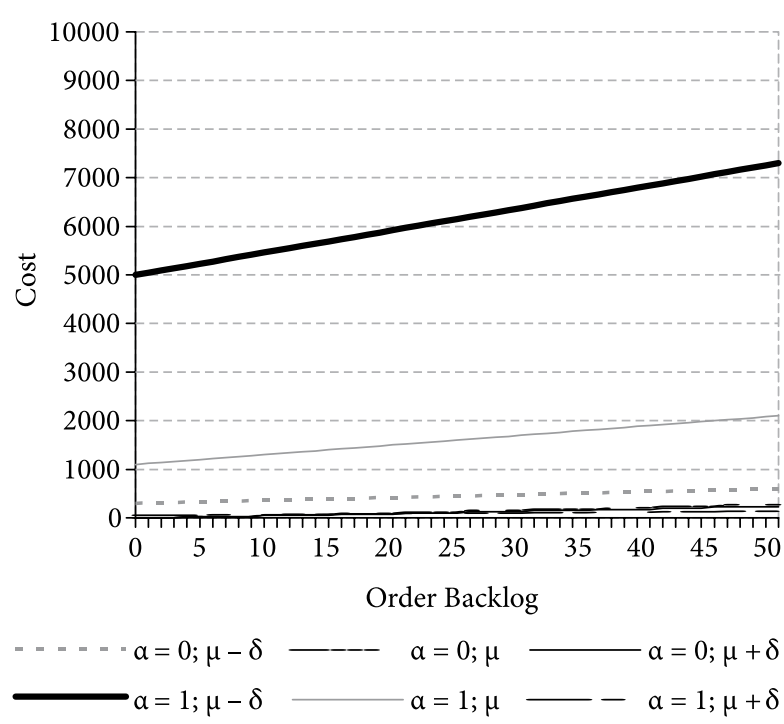

Fig. 2. Optimal cost for given backlog for discrete uniform demand and backlogged cost $3 B^{2}$

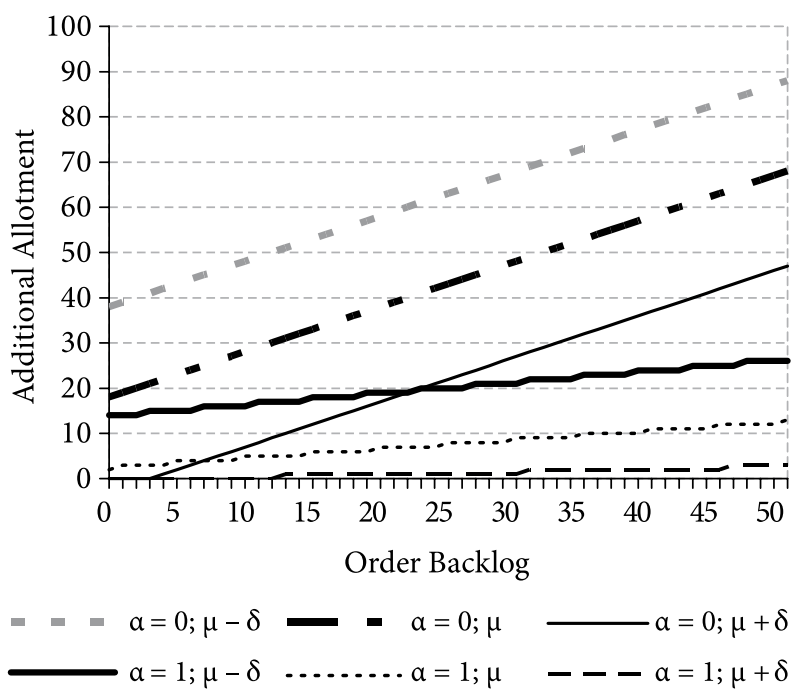

Fig. 3. Optimal additional allotment for given backlog for discrete uniform demand and backlog cost $3 B^{2}$ 
lotment at stage 1 does not deviate largely for different discrete and symmetrical distributions indicating that the optimal results are robust for symmetrical distributions. The results of the runs have also shown that for different backlogged cost functions at the last stage, the optimal quantities of additional allotment at stage 1 differ only marginally. One of the reasons is that the last stage effect diminishes quickly as one move back to stage 1 .

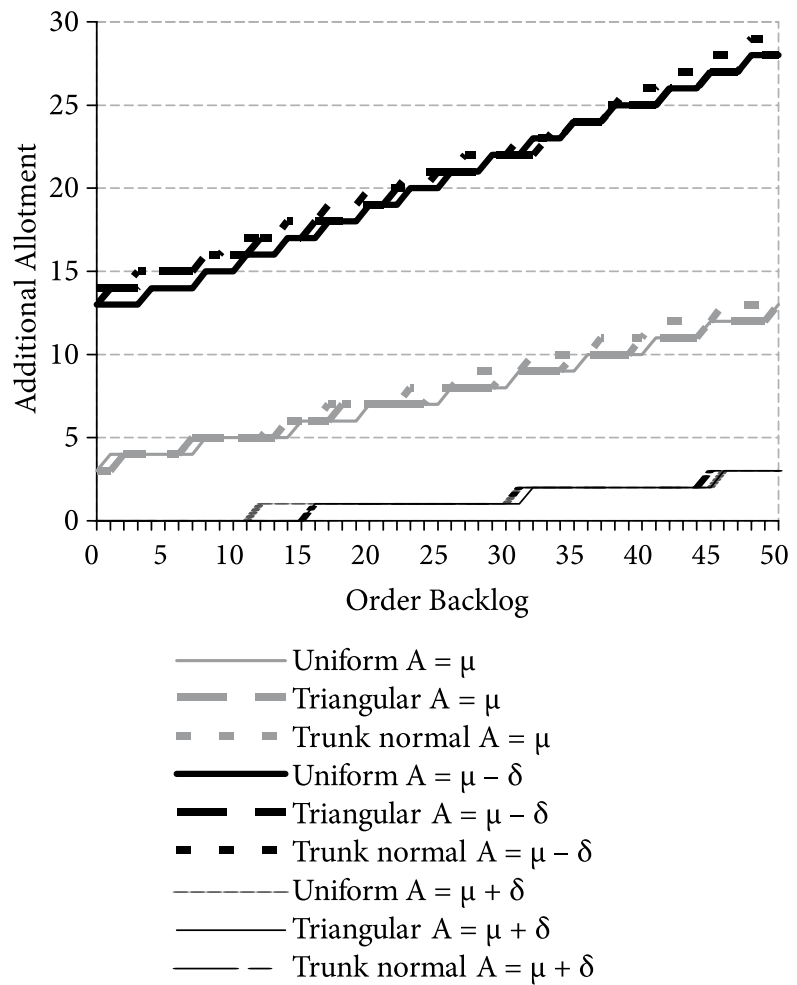

Fig. 4. Optimal additional allotment for given backlog when additional allotment cost function is $R^{2}+R$ and backlogged cost $3 B^{2}$

\section{Conclusions}

1. The paper presents a model and solution procedure for solving a problem of allotments in a shuttle train for transport units. Forwarders should balance the cost of late deliveries against the cost of having too much allotment.

2. This model could be applicable in the growing market of transporting trucks and containers by shuttle trains in East Europe where forwarders have experienced great frustration in trying to manage the uncertainty of production and demand for free railcars available by a shuttle-train.

3. The ideas presented in this paper can also be used to determine the amount of long-term contract space that should be purchased.

\section{References}

Ballis, A.; Golias, J. 2004. Towards the improvement of a combined transport chain performance, European Journal of Operational Research 152(2): 420-436.
Bookbinder, J. H.; Fox, N. S. 1998. Intermodal routing of CanadaMexico shipments under NAFTA, Transportation Research Part E: Logistics and Transportation Review 34(4): 289-303.

Burkovskis, R. 2008. Efficiency of freight forwarder's participation in the process of transportation, Transport 23(3): 208-213.

Chew, E.-P.; Huang, H.-C.; Ellis L.; Johnson, G. L.; Nemhauser, J. S.; Sokol, J. S.; Leong, C.-H. 2006. Short-term booking of air cargo space, European Journal of Operational Research 174(3): 1979-1990.

Evers, P. T. 1994. The Occurrence of statistical economies of scale in intermodal transportation, Transportation Journal 33(4): 51-62.

GETC/G4384/SPR. 2003. Combined transport: a viable solution. International Road Transport Union, IRU. 5 p.

Ibaraki, T.; Imahori, S.; Kubo, M.; Masuda, T.; Uno, T.; Yagiura, M. 2005. Effective local search algorithms for routing and scheduling problems with general time-window constraints, Transportation Science 39(2): 206-232.

Jaržemskienè, I. 2007. The evolution of intermodal transport research and its development issues, Transport 22(4): 296-306.

Jaržemskis, A. 2005. The model of allotments booking in a shuttle train, Transport 20(6): 236-239.

Jaržemskis, A. 2008. Assumptions of small-scale intermodal transport, Transport 23(1): 16-20.

Joborn, M.; Crainic, T.G.; Gendreau, M.; Holmberg, K.; Lundgren, J. T. 2004. Economies of scale in empty freight car distribution in scheduled railways, Transportation Science 38(2): 121-134.

Lingaitiene, O. 2008. A mathematical model of selecting transport facilities for multimodal freight transportation, Transport 23(1): 10-15.

Lowe, D. 2005. Intermodal Freight Transport. ButterworthHeinemann Publisher, 304 p.

Miao, X.; Xi, B. 2008. Agile forecasting of dynamic logistics demand, Transport 23(1): 26-30.

Raman, A. 1999. Managing inventory for fashion products, in Quantitative Models for Supply Chain Management, edited by Tayur, S.; Ganeshan, R.; Magazine, M., 1st edition. Springer, 789-806.

Šakalys, A.; Palšaitis, R. 2006. Development of intermodal transport in new European Union states, Transport 21(2): 148-153.

Trip, J. J.; Bontekoning, Y. 2002. Integration of small freight flows in the intermodal transport system, Journal of Transport Geography 10(3): 221-229.

Vasilis Vasiliauskas, A. 2006. Modeling performance of railways nodes as intermodal terminals, Transport 21(3): 155-159.

Vasilis Vasiliauskas, A.; Barysienė, J. 2008a. Analysis of Lithuanian transport sector possibilities in the context of European-Asian trade relations, Transport 23(1): 21-25.

Vasilis Vasiliauskas, A.; Barysienè, J. 2008b. An economic evaluation model of the logistic system based on container transportation, Transport 23(4): 311-315.

Vasilis Vasiliauskas, A.; Jakubauskas, G. 2007. Principle and benefits of third party logistics approach when managing logistics supply chain, Transport 22(2): 68-72.

White Paper - European transport policy for 2010: time to decide. 2001. European Commission, Luxembourg: Office for Official Publications of the European Communities. 119 p. Available from Internet: <http://ec.europa.eu/transport/ white_paper/documents/doc/lb_texte_complet_en.pdf $>$.

Wu, P.; Hartman, J. C.; Wilson, G. R. 2005. An Integrated Model and Solution Approach for Fleet Sizing with Heterogeneous Assets, Transportation Science 39(1): 87-103. 